\title{
Unusually devastating tornadoes in the United States: 1995-2016
}

\author{
Tyler Fricker *, James B. Elsner \\ Florida State University
}

${ }_{2}{ }^{*}$ Corresponding author address: Tyler Fricker, Florida State University, Department of Geography,

3 Florida State University, 113 Collegiate Loop, Tallahassee, FL 32306.

4 E-mail: tfricker@fsu.edu 
ABSTRACT

5 Previous research has identified a number of physical, socioeconomic, and

6 demographic factors related to tornado casualty rates. However, there remains

7 gaps in our understanding of community-level vulnerabilities to tornadoes.

8 Here a framework for systematically identifying the most unusually devastat-

9 ing tornadoes, defined as those where the observed number of casualties far

10 exceeds the predicted number, is provided. Results show that unusually dev-

11 astating tornadoes occur anywhere tornadoes occur in the United States, but

12 rural areas across the Southeast appear to be most frequented. Five examples

${ }_{13}$ of unusually devastating tornadoes impacting four communities are examined

14 in more detail. In addition, results highlight that cities and towns impacted

${ }_{15}$ by unusually devastating tornadoes have their own socioeconomic and de-

${ }_{16}$ mographic profiles. Identifying geographic clusters of unusually devastating

${ }_{17}$ tornadoes builds a foundation to address community-level causes of destruc-

${ }_{18}$ tion that supports ethnographic and qualitative - in addition to quantitative-

19 studies of place-based vulnerability. 


\section{Introduction}

Tornadoes are one of the deadliest weather-related hazards in the United States. Wind energy and population density explain a large portion of tornado casualty rates (Ashley et al. 2014; Ashley and Strader 2016; Fricker et al. 2017a; Elsner et al. 2018), but socioeconomic and demographic factors also play a role (Bohonos and Hogan 1999; Mitchem 2003; Simmons and Sutter 2005, 2008, 2009; Donner 2007; Ashley 2007; Dixon and Moore 2012; Donner et al. 2012; Lim et al. 2017; Strader and Ashley 2018). For example, Simmons and Sutter (2005, 2008, 2009) find that casualties increase with an increase in the percentage of mobile homes in an area affected. Other known factors include time of day (Simmons and Sutter 2005, 2008, 2009; Ashley et al. 2008), and day of occurrence (workday or weekend) (Zahran et al. 2013).

Identifying the physical, socioeconomic, and demographic factors related to tornado casualty rates is critical for understanding human vulnerability to these potentially devastating events. However, there remains a gap in our knowledge around why some communities are particularly vulnerable to tornadoes. For example, the Spencer, South Dakota tornado of 30 May, 1998 resulted in six deaths and 150 injuries, which is nearly half of the town's population.

In an effort to fill this knowledge gap, here a framework for systematically identifying the most unusually devastating tornadoes is provided. We begin by defining unusually devastating tornadoes. This is done with the help of a statistical model for predicting per-tornado casualty rates. Next, the set of unusually devastating tornadoes since 1995 are identified by examining the difference between what is predicted from the statistical model and what was observed on the ground. More specifically, after statistically conditioning on the known physical and socioeconomic determinants of casualties, we identify what tornadoes were unusual in producing more casualties than 
expected based on where they hit. In addition, we discuss examples of locations that were hit with unusually devastating tornadoes.

\section{Factors Related to the Number of Casualties}

Tornadoes kill and injure nearly one thousand people, on average, in the United States each year. Previous research has identified physical factors that impact the rate of tornado casualties. These include the maximum damage rating (Fujita/Enhanced Fujita (F/EF) scale), the tornado damage path length, and the strength, or energy dissipation, of the tornado. For example, Ashley (2007) finds that tornadoes categorized with a high maximum damage rating (F scale) produce the vast majority of tornadoes fatalities, while Fricker et al. (2017b) show that tornadoes with a high maximum damage rating (EF scale) represent a disproportionate number of casualty-producing tornadoes relative to the total number of tornadoes. In addition, Simmons and Sutter $(2005,2008$, 2009) and Lim et al. (2017) find that as tornado damage path length increases, so does the number of tornado casualties. Quantitatively, Fricker et al. (2017a) note that a doubling of tornado strength, represented as an estimate of energy dissipation, leads to a $33 \%$ increase in the rate of tornado casualties.

Previous research has also identified a number of socioeconomic and demographic factors that impact the rate of tornado casualties. These include the number of people in harm's way, the type of housing stock present (permanent or mobile), and the age and income of the population within the damage path. For instance, Simmons and Sutter $(2008,2009)$ and Fricker et al. (2017a) find that the number of tornado casualties increases with population density. Similarly, Simmons and Sutter $(2005,2008,2009)$ find that the number of tornado casualties increases with the percentage of mobile homes within an area. This result is further supported by Ashley (2007) and Strader and Ashley (2018), who note that more than half of all housing-related tornado fatalities between 
1985-2017 occurred in mobile homes. Bohonos and Hogan (1999) posit that the number of tornado casualties may increase with age, due to the elderly being less likely to receive warning and being less mobile and more likely to have health issues (Kilijanek and Drabek 1979; Bolin and Klenow 1983; Cutter et al. 2000; Dixon and Moore 2012).

Additional factors such as race, poverty, education, and sex of household head have been linked to the rate of tornado casualties as well. Donner (2007) hypothesizes that African-Americans are likely more vulnerable to tornado casualties, in part, because they may have more difficulty understanding warning messages (Mitchem 2003). Lim et al. (2017) find that wealthier communities experience fewer tornado casualties and that female-headed households are more vulnerable to tornado casualties than two-parent households or male-headed households, both of which are consistent with previous natural hazard research (Bosworth 1999; Anbarci et al. 2005; Kahn 2005; Enarson et al. 2007).

Regression models are used to determine what factors are important in statistically explaining casualties and to quantify the effect a single factor has on casualties while conditioning on the other factors. For example, using county-level socioeconomic and demographic data with a straight line model for the tornado 'footprint' Simmons and Sutter (2014) predict per-tornado fatalities of events during the active 2011 season. Fricker et al. (2017a) use a more detailed model for the tornado footprint and produce tornado-level estimates of energy dissipation and population with a dasymetric approach on grid-level data. They find that the rate of tornado casualties increases with population and energy dissipation and label the regression coefficients the population and energy elasticity, respectively. Masoomi and van de Lindt (2018) use a similar detailed footprint model to produce tornado-level estimates of population and housing units from Census block-level data and improve on the predictive skill of Simmons and Sutter (2014) using the maximum damage rating, path length, and the number of people within the damage path as fixed effects. More re- 
cently, Elsner et al. (2018) improve on the Fricker et al. (2017a) model by including an interaction between energy dissipation and population density. They find that the energy elasticity increases significantly with population density and that the population elasticity increases significantly with energy dissipation.

\section{Unusually Devastating Tornadoes}

\section{a. Definition}

Knowing the physical, demographic, and environmental factors that influence casualty rates provides guidance on how to communicate the risk across a broad segment of society. For example, the regression model of Elsner et al. (2018) predicts a casualty rate of 20 people (per casualtyproducing tornado) for a $100 \mathrm{GW}$ tornado affecting an area with a population density of 1500 people per square kilometer. This predicted rate represents the average, or expected, count given specific values for the factors without regards to where the tornado occurs. However, local, placebased, factors are also usually important in mitigating or amplifying casualty rates. To locate places where local factors might be particularly important we examine the residuals from a regression model and define an unusually devastating tornado as one where the observed number of casualties substantially exceeds the predicted rate.

More formally, let $C_{T}$ be the observed casualty count for tornado $T$ and $\hat{C}_{T}$ be the predicted casualty rate for the same tornado from a regression model $f$ involving known tornado-level factors $\mathbf{x}_{T}$ (e.g. population density, energy dissipation, number of mobile homes, etc). We then define an unusually devastating tornado as one in which the difference between $C_{T}$ and $\hat{C}_{T}$ exceeds some 
large value $(L)$ (see Eq. 1 and Section 3c).

$$
\begin{aligned}
\mathrm{UDT}_{T} & =C_{T}-\hat{C}_{T}>L \\
\hat{C}_{T} & \sim f\left(\mathbf{x}_{T}\right),
\end{aligned}
$$

In what follows we fit a regression model to the casualty counts and examine the differences between what the model predicts and what actually occurred. We are particularly interested in where the tornadoes occurred that resulted in a large difference between the observed count and the predicted count.

\section{b. Model and data}

We fit a log-linear regression model to the casualty count of all casualty-producing tornadoes occurring in the United States between 1995-2016. The model is described in detail in Elsner et al. (2018) and includes energy dissipation and population density as the two most important factors that statistically explain casualties. Energy dissipation (power) in units of watts is defined as the product of path area, air density, and the weighted sum of the velocity cubed. The summation is over the six possible damage ratings and the weights are the fractions of path area by damage rating. Velocities are set as the midpoint wind speed defined by the EF scale (Fricker et al. 2014;

Fricker and Elsner 2015; Fricker et al. 2017a; Elsner et al. 2018). Population density is the number of people per square kilometer within the damage path of the tornado.

Here the model of Elsner et al. (2018) is expanded to include the number of mobile homes within the path and the year of occurrence as additional fixed effects and month and hour of occurrence as random effects. Month and hour of occurrence are included as random effects to capture the cyclic change in energy at these respective time scales (Fig. 1). The coefficients on month and hour 
of occurrence are elements of vectors of length 12 and 24, respectively. The number of mobiles homes are estimated using a dasymetric method similar to the procedure used in Fricker et al. (2017b), where weighted estimates of mobile homes are made for each fraction of the tornado path and summed for the entire tornado path.

Formally, the model is given by

$$
\begin{aligned}
\ln (C) & =\ln \left(\beta_{0}\right)+\beta_{P} \ln (P)+\beta_{E} \ln (E)+\beta_{P \cdot E}[\ln (P) \cdot \ln (E)]+\beta_{Y} Y \\
& +\beta_{M H} M H+\boldsymbol{\beta}_{M O}(1 \mid M O)+\boldsymbol{\beta}_{H R}(1 \mid H R)
\end{aligned}
$$

where $P$ is the population density in people per square kilometer, $E$ is energy dissipation in watts, $Y$ is the year of occurrence, $M H$ is the estimated number of mobile homes, and $M O$ and $H R$ are the month and hour of occurrence, respectively.

Our modeling approach is similar to that of recent work that examines factors related to tornado casualties (Donner 2007; Simmons and Sutter 2008, 2011; Zahran et al. 2013; Lim et al. 2017). However, here we use tornado power (energy dissipation) rather than EF rating or total damage as an indicator of tornado strength and we focus on factors influencing the casualty rate among those tornadoes producing at least one casualty.

Tornado report information is from the Storm Prediction Center's (SPC) historical tornado database, which is compiled from the National Weather Service (NWS) Storm Data and reviewed by the National Centers for Environmental Information (NCEI) (Verbout et al. 2006). The start year for this study coincides with the period of record where maximum path width was adopted by NWS. The end year for this study is the most currently available to the authors at the time of analysis. A casualty is defined by the NWS as a direct injury or fatality directly attributable to the tornado event itself. Population and mobile home data are obtained from the United States Census Bureau and American Community Survey (ACS), which is a nationwide survey that collects and 
produces information on demographic, social, economic, and housing characteristics each year. Population and mobile home estimates are made at the tract-level.

The Pearson correlation coefficient between the observed and predicted rate of casualties for all casualty-producing tornadoes in the study is .50 , indicating a moderately good relationship. When a subset of the largest casualty-producing tornadoes - tornadoes causing 25 or more casualties-is considered, the relationship becomes stronger (Fig. 2). This suggests that the model is adequate for assessing UDTs.

\section{c. Where UDTs Occur}

For the set of casualty-producing tornadoes (2198 tornadoes) over the period, the model underpredicted the observed count for 491 tornadoes. Of these 491, 101 were underpredicted by ten or more casualties, while 43 (90th percentile) were underpredicted by 22 or more casualties. A tornado that results in an underprediction at the 90th percentile is defined here as an UDT. For example, given the storm's power and the demographic profile in its path the 26 December, 2015 Garland-Rowlett, Texas tornado has an expected casualty rate of 81 . The tornado produced 478 casualties, which is a difference of 397 casualties so it is categorized as an UDT. Nine of the top ten UTDs ranked by the difference in predicted and observed casualty rates (Table 1) resulted in more than 100 casualties. The Joplin, Missouri tornado of 22 May, 2011 stands out as the most UDT. Given estimates of physical and socioeconomic factors, the model predicts a casualty rate of 131 people. In fact, the tornado produced 1308 casualties-a difference of 1177 casualties. The choice of the 90th percentile for defining a UDT is arbitrary but it focuses our attention to the most unusually destructive tornadoes.

Unusually devastating tornadoes can occur anywhere in the United States where a tornado impacts a populated area (Fig. 3). However rural areas across the Southeast appear to be where 
we find more unusually devastating tornadoes. Indeed, six of the top ten UDTs ranked by the difference in predicted and observed casualty rates occur in the Southeast (Arkansas, Alabama, Georgia, Mississippi, and North Carolina). Two of the top ten occurred in Texas, and one of the top ten occurred in both Missouri and in South Dakota. It is likely the disproportionate distribution of UDTs across portions of the rural Southeast is driven by a combination of physical and social vulnerabilities, including an increased risk of significant and long-tracked tornadoes (Dixon et al. 2011; Coleman and Dixon 2014), as well as higher percentages of persons and households that are black (or minority), unemployed, in poverty, on disability, part of the Supplemental Nutrition Assistance Program (SNAP), or headed by a single female (Cutter et al. 2003; Emrich and Cutter 2011; Strader and Ashley 2018).

\section{Examples of Unusually Devastating Tornadoes}

Highlighting examples of unusually devastating tornadoes underscores the fact that UDTs can occur anywhere in the United States. Here five examples of unusually devastating tornadoes impacting four communities are investigated: (1) the 1998 Spencer, South Dakota tornado, (2) the 2015 Garland-Rowlett, Texas tornado, (3) the 2000 and 2003 Camilla, Georgia tornadoes, and (4) the 2011 Smithville, Mississippi/Shottsville, Alabama tornado. The examples are chosen to provide a wide spatial distribution of impacted communities. The cities range from a small rural town in the northern Great Plains, to small cities and towns in the Southeast, to mid-size urban/suburban cities in the southern Great Plains. These cities have their own individual socioeconomic and demographic profiles, yet were all hit by tornadoes that caused more casualties than expected given a model for tornado casualties. The purpose of highlighting these examples is to bring attention to the complexity and potential uniqueness of each case of an unusually devastating tornado. It is not 
to find the specific reason or set of reasons for the high rate of tornado casualties - as there may never be an easily identifiable reason or set of reasons for high casualty rates.

\section{a. Spencer, South Dakota}

Spencer is a rural town in southeast South Dakota (Fig. 4). As of the 2010 Census, Spencer had a population of 154 people, including 60 households, and 47 families. The age structure of the city is $30 \%$ under the age of $18 ; 2 \%$ from 18 to $24,19 \%$ from 25 to $44,25 \%$ from 45 to 64 , and $24 \%$ over the age of 65 years. The racial makeup of the city is $97 \%$ White and $1 \%$ African American. About $7 \%$ of families and $11 \%$ of the total population are below the poverty line. The median household income in the city is $\$ 21,250$ and $7 \%$ of families and $11 \%$ of the total population are below the poverty line.

Spencer was hit by a violent tornado (EF4) on 30 May, 1998. The tornado killed six people and injured more than one third of the city's residents. It also destroyed most of the 190 buildings in town and resulted in $\$ 18$ million in property damage. The tornado was part of a supercell thunderstorm that produced 5 tornadoes during a one hour period.

The 1998 Spencer, South Dakota storm started at approximately 7:35pm Eastern Standard Time (EST) southwest of Wessington Springs, South Dakota-about 60 miles west-northwest of Spencer. The storm almost immediately split into left and right moving cells with the right moving cell becoming a mid-level mesocyclone at 9:26pm EST. By 9:28pm EST, Sioux Falls radar (WSR-88D) had indicated a hook echo and well-defined rotation. From 9:23pm-9:37pm EST, the Spencer tornado tracked through farmland, within 1 mile of the town of Farmer, before striking the town of Spencer. The city of Spencer experienced violent tornado conditions from 9:38pm-9:39pm EST, before the storm dissipated at 10:10pm EST. 


\section{b. Garland-Rowlett, Texas}

Garland and Rowlett are two mid-size cities in the Dallas-Fort Worth metroplex in north Texas (Fig. 4). As of the 2010 Census, Garland had a population of 226,876 people, including 75,696 households and 56,272 families. The age structure of the city is $29 \%$ under the age of $18,10 \%$ from 18 to $24,28 \%$ from 25 to $44,25 \%$ from 45 to 64 , and $9 \%$ over the age of 65 . The racial makeup of the city is 58\% White, 15\% African American, and 9\% Asian. The median household income in the city is $\$ 52,441$, and $11 \%$ of families and $14 \%$ of the total population are below the poverty line.

As of the 2010 Census, Rowlett had a population of 56,310 people, including 22,875 households, and 17,275 families. The age structure of the city is $34 \%$ under the age of $18,6 \%$ from 18 to 24 , $37 \%$ from 25 to $44,19 \%$ from 45 to 64 , and $5 \%$ over the age of 65 . The racial makeup of the city is 78\% White, 9\% African American, and 4\% Asian. The median household income in the city is $\$ 100,872$, and only $2 \%$ of families and $3 \%$ of the total population are below the poverty line.

Garland and Rowlett were hit by a violent tornado (EF4) on 26 December, 2015. The tornado killed 10 and injured more than 400 people, while producing $\$ 26$ million in property damage. It was part of the north Texas tornado outbreak of 26 December, 2015 that produced 12 tornadoes, causing 13 fatalities across eight north and central Texas counties.

The 2015 Garland-Rowlett, Texas tornadic storm formed near Hillsboro around 7:00pm EST. The storm strengthened as it moved north-northeast through Waxahachie at 7:45pm EST, spawning two tornadoes just south of Dallas. As the storm moved north of Dallas, it again became tornadic near Sunnyvale passing through the cities of Garland and Rowlett between 8:46pm-9:02pm EST, before dissipating around McKinney at 9:30pm EST. 


\section{c. Camilla, Georgia}

Camilla is a small city in southwest Georgia (Fig. 4). As of the 2010 Census, Camilla had a population of 5360 . The age structure of Camilla is $30 \%$ under the age of $18,11 \%$ from 18 to $24,27 \%$ from 25 to $44,19 \%$ from 45 to 64 , and $13 \%$ over the age of 65 . The racial makeup of the town is 70\% African American and 25\% White. The median household income in the town is $\$ 22,485$, and $35 \%$ of families and $38 \%$ of the total population are below the poverty line.

Camilla was hit by two significant tornadoes in the early 2000s, both occurring in the early morning and both traveling through the southeast side of town. The first tornado (EF3) occurred on 13 February, 2000 and resulted in 186 casualties. According to the American Red Cross (ARC) and Federal Emergency Management Agency (FEMA), 200 homes were destroyed and 250 homes were damaged resulting in $\$ 20$ million in property damage. The second tornado (EF3) occurred on 20 March, 2003 and resulted in 206 casualties. It took a similar path to the 2000 tornado and according to the ARC and FEMA destroyed 66 homes while damaging another 200.

The 2000 Camilla, Georgia tornado was part of the larger southwest Georgia tornado outbreak of 13-14 February, 2000. Beginning Sunday evening, and continuing into the early morning hours of Monday, the National Weather Service (NWS) Tallahassee issued 52 severe weather warnings, including 25 tornado warnings. During the outbreak, three deadly tornadoes caused 19 fatalities across three Georgia counties.

The 2000 Camilla tornadic storm came ashore in extreme southeast Walton County, Florida at around 8:30pm EST. The storm weakened as it crossed Lake Seminole, the dividing line between Florida, Alabama, and Georgia, around 11:00pm EST, before strengthening near the boundary of Seminole County, Georgia. The storm became tornadic around 11:42pm near Branchville, 
remaining tornadic as it passed just south of Camilla before dissipating east-northeast of the city around 12:05am EST.

The 2003 Camilla, Georgia tornado was part of the larger 20 March, 2003 outbreak in northern Florida and southwestern Georgia, which included two deadly tornadoes. These two tornadoes caused six fatalities, hundreds of injuries, and a path of destruction that extended from the Florida Panhandle coast all the way into central Georgia.

The 2003 Camilla tornadic storm initially came ashore in extreme southwest Bay County, Florida, at approximately 2:30am EST. The cell rapidly developed circulation and may have become tornadic in the northern part of the county. The storm destroyed a home in Fountain, Florida around 3:07am EST before continuing across the northeastern Florida Panhandle into Jackson County, Florida where the first confirmed tornado occurred. The parent storm again became tornadic as it crossed into Mitchell County impacting the city of Camilla at around 5:12am EST, before dissipating east-northeast of the city around 5:30am EST.

\section{d. Smithville, Mississippi/Shottsville, Alabama}

Smithville, Mississippi and Shottsville, Alabama are two rural towns near the northern Mississippi-Alabama border (Fig. 4). As of the 2010 Census, Smithville had a population of 942 people, including 365 households. The age structure of the city is $24 \%$ under the age of 18 , $10 \%$ from 18 to $24,25 \%$ from 25 to $44,25 \%$ from 45 to 64 , and $16 \%$ over the age of 65 . The racial makeup of the city is $96 \%$ White and $2 \%$ Africa American. The median household income in the city is $\$ 32,583$, and $7 \%$ of families and $11 \%$ of the total population are below the poverty line.

As of the 2010 Census, Shottsville was an unincorporated town in Marion County, Alabama which had not participated in any Census or other population survey. If we assume Marion County 
as a representative sample of Shottsville, the age structure of the town is $22 \%$ under the age of 18 , $8 \%$ from 18 to $24,24 \%$ from 25 to $44,28 \%$ from 45 to 64 , and $18 \%$ over the age of 65 . The racial makeup of the town is $94 \%$ White and $4 \%$ African American. The median household income in the town is $\$ 32,769$, and $13 \%$ of families and $18 \%$ of the total population are below the poverty line.

Smithville and Shottsville were hit by a violent tornado (EF5) on April 27, 2011. The tornado killed 23 and injured 137 people. It was part of the Super Outbreak of 25-28 April, 2011 that produced 360 tornadoes, causing 324 fatalities and over 3100 injuries.

The 2011 Smithville, Mississippi/Shottsville, Alabama tornado formed a few miles westsouthwest of Smithville along the Tennessee-Tombigbee Waterway at 3:42pm EST. The storm strengthened as it moved toward and through Smithville, reaching EF5 intensity. It continued northeast across the Alabama state line into Marion County, where it weakened as it moved near the small town of Bexar. The storm again strengthened as it struck the town of Shottsville around 4:00pm EST, before dissipating near Hodges at 4:23pm EST.

\section{e. Synthesizing the Results of Communities Impacted by UDTs}

The above survey of examples of communities impacted by UDT makes it clear that no single socioeconomic or demographic variable will explain high casualty rates across all tornadoes (Table 2). For example, while having a low median household income or high rate of poverty will, on average, exacerbate the number of tornado casualties experienced by a community, these factors cannot be blamed for the high casualty count of the 2015 Garland-Rowlett, Texas tornado. Similarly, while having a relatively large number of elderly residents will, on average, lead to an increased number of tornado casualties felt by a community, this factor is not what caused the high casualty counts of the 2000 and 2003 Camilla, Georgia tornadoes. 
For the few socioeconomic factors considered in this study, it is obvious that many of the communities impacted by unusually devastating tornadoes suffer from limited resources, in part due to a lack of disposable income. For example, the average median household income for these four communities is $\$ 38,267$, which is well below the median United States household income of $\$ 61,822$. When Garland and Rowlett, Texas are removed from consideration, the average household median for the remaining three communities (Spencer, South Dakota, Camilla, Georgia, and Smithville, Mississippi/Shottsville, Alabama) is $\$ 25,470$, which is less than half of the median United States household income. That said, other than in Camilla, Georgia, poverty rates do not seem to be a driving force in the rate of tornado casualties—at least in these four communities. In fact, the average rate of poverty for both families and population of the three remaining communities (Spencer, South Dakota, Garland-Rowlett, Texas, and Smithville, Mississippi/Shottsville, Alabama) impacted by unusually devastating tornadoes are consistent with the United States' average of $9 \%$ and $12 \%$, respectively.

For the few demographic factors considered in this study, it is more difficult to tease out reasons for why these communities were impacted by unusually devastating tornadoes. There is no large difference in the percentage of people over the age of 65 in these communities and the United States' average. Perhaps the number of young people (under the age of 18) contributed to the rate of tornado casualties in these communities. Indeed, the average percentage of people under the age of 18 in these four communities is $28 \%$, which is slightly higher than the United States' average of $24 \%$. Race does not appear to make a large difference, as these four communities range from predominately white (Spencer, South Dakota, Smithville, Mississippi/Shottsville, Alabama) to predominately black (Camilla, Georgia).

In summarizing the socioeconomic and demographic profiles of the communities hit by UDTs, it is apparent that establishing causal relationships between descriptive variables and the rate of 
tornado casualties requires a bespoked approach. While indices like the Social Vulnerability Index (SoVI) (Cutter et al. 2003), and the Socioeconomic and Demographic Vulnerability Index (SEDVI) (Strader and Ashley 2018) are useful in understanding the broad scale patterns of factors that influence physical, social, and human vulnerability, they have limited utility at smaller scales. This is especially true of research that relies on statistical analysis, because many of the variables included in the vulnerability indices are confounding (e.g. median household income and race, family structure and education, renters and occupation). As such, for work with the goal of intervening — reducing the number of tornado casualties—in the tornado casualty problem, it does not help to simply add more variables to a model and interpret the coefficients. There are likely systems in place (e.g. institutionalized poverty, distrust of government, etc.) and various scales in many of these communities that contribute to the presence of unusually devastating tornadoes. Additionally, it is also likely that unique situations—cultural events-contribute to the presence of unusually devastating tornadoes. For example, the 2011 Joplin, Missouri tornado took place on the same day as a high school graduation and the 2015 Garland-Rowlett, Texas tornado took place on the day after Christmas. Accounting for these factors statistically is difficult, but should be considered in more detail moving forward.

\section{Summary}

Broad-scale factors that contribute to the number of tornado casualties are well understood. These factors range from physical variables, such as wind energy and EF category (Ashley 2007; Fricker et al. 2017a), to socioeconomic and demographic variables, such as population and the number of mobile homes (Simmons and Sutter 2008, 2009). Place-based factors that contribute to the number of tornado casualties have yet to be systematically examined. For example, research committed to uncovering the shared histories—both archival and oral histories—of communities 
(McCreary 2018) at risk to high rates of tornado casualties does not exist. Neither does work centered around the lines of labor (e.g. labor displacements) and housing (e.g. post-reconstruction housing) that potentially influence the susceptibility of areas to large numbers of tornado casualties.

Here a model for tornado casualties is used to define unusually devastating tornadoes and to identify where they cluster. The model builds on the work of Fricker et al. (2017a) and Elsner et al. (2018), but is similar to that of recent work that examines factors related to tornado casualties (Donner 2007; Simmons and Sutter 2008, 2011; Zahran et al. 2013; Lim et al. 2017). Given the Pearson correlation coefficient between the observed and predicted rate of casualties at .50 , the model appears adequate for assessing UDTs and is therefore useful in identifying where UDTs occur most often.

Adding variables to the model will certainly increase the explanatory power of the model, but it is not clear that doing so would bring us closer to answering questions about why some communities are more prone to high tornado casualty rates. One way to attack this question is to ground future work in the communities in which unusually devastating tornadoes tend to cluster or reappear. This can be done, in part, through research using ethnographic and other qualitative methodologies (Sherman-Morris 2009; Senkbeil et al. 2012, 2013; Klockow et al. 2014; Ash 2016; Ellis et al. 2018; Mason et al. 2018).

While unusually devastating tornadoes can occur anywhere in the United States, there appears to be a consistent presence of UDTs across rural portions of the Southeast. In fact, six of the top ten UDTs ranked by the difference in predicted and observed casualty rates occur in the Southeast (Arkansas, Alabama, Georgia, Mississippi, and North Carolina), in small cities and towns not known as urban centers. Two of the top ten occurred in Texas, and one of the top ten occurred in Missouri and in South Dakota. Though it is likely that a combination of physical and social 
vulnerabilities influence this disproportionate spatial distribution of UDTs, it is uncertain that the number of people or the number of mobile homes within the tornado's path are to blame for the casualty numbers-as the modeled rates are conditioned on these variables.

Five examples of unusually devastating tornadoes impacting four communities are further examined. These include (1) the 1998 Spencer, South Dakota tornado, (2) the 2015 Garland-Rowlett, Texas tornado, (3) the 2000 and 2003 Camilla, Georgia tornadoes, and (4) the 2011 Smithville, Mississippi/Shottsville, Alabama tornado. After investigating the demographic and socioeconomic profiles of these communities, it is clear that no one factor is to blame for the high casualty rates found in UDTs. While median household income and rates of poverty are likely to increase the rate of tornado casualties, they did not largely influence the number of tornado casualties found in the 2015 Garland-Rowlett, Texas tornado. Similarly, while a higher percentage of young people in a community is likely to increase the rate of tornado casualties, it did not largely influence the number of tornado casualties found in the 2011 Smithville, Mississippi/Shottsville, Alabama tornado.

After investigating the demographic and socioeconomic profiles of communities impacted by tornadoes where predicted rates of tornado casualties were high, but observed casualties were low (Fig. 2), it is also clear that no one factor dictates resiliency and adaptive capacity and that communities can have similar vulnerabilities, yet have different casualty outcomes. Examples of these tornadoes on the opposite side of UDTs include (1) the 1997 Detroit, Michigan tornado, (2) the East Nashville, Tennessee tornado, (3) the 1999 Bridge Creek-Moore, Oklahoma tornado, and (4) the 2011 Hackleburg-Phil Campbell, Alabama tornado. Surprisingly, many of these impacted communities also suffer from low median household income and high rates of poverty (e.g. Eight Mile Road/Hamtramck, Michigan, Hackleburg/Phil Campbell, Alabama). Thus, if the goal is to successfully intervene in the tornado casualty problem, it remains important to move beyond- 
but not necessarily in place of-statistical or systematic indices (e.g. SoVI, SEDVI) that define vulnerabilities, as no single variable or group of variables will easily define a causal relationship between tornado casualties and vulnerability, resiliency, or adaptive capacity.

By identifying clusters of unusually devastating tornadoes, this research provides a foundation to address community-level causes of destruction. These factors might include the history of tornado occurrence (physical risk), the NWS county warning area, lines of labor (e.g. labor displacements), lines of housing (e.g. history of mobile homes), or other structures. Though it is unlikely that all areas impacted by UDTs have the same shortcomings in public safety or in other potential causes of vulnerability, it is possible that some areas, particularly those communities experiencing multiple UDTs suffer from more systematic issues. By recognizing these communities throughout the United States, this research stands to confront the current paradigm of 'responsibilization' in hazards—-particularly tornado—and vulnerability literature (Begg et al. 2016).

Acknowledgments. Part of this research benefited from discussions with Tyler McCreary. The code used to produce the tables and graphs is available at https://github.com/tfricker/ Unusually-Devastating-Tornadoes.

\section{References}

Anbarci, N., M. Escaleras, and C. A. Register, 2005: Earthquake fatalities: the interaction of nature and political economy. Journal of Public Economics, 89 (9-10), 1907-1933, doi:10.1016/ j.jpubeco.2004.08.002, URL https://doi.org/10.1016/j.jpubeco.2004.08.002.

Ash, K. D., 2016: A qualitative study of mobile home resident perspectives on tornadoes and tornado protective actions in south carolina, USA. GeoJournal, 82 (3), 533-552, doi:10.1007/ s10708-016-9700-8, URL https://doi.org/10.1007/s10708-016-9700-8. 
Ashley, W., 2007: Spatial and temporal analysis of tornado fatalities in the United States: 18802005. Weather and Forecasting, 22, 1214-1228.

Ashley, W. A., A. J. Krmenec, and R. Schwantes, 2008: Vulnerability due to nocturnal tornadoes. Weather and Forecasting, 23, 795-807.

Ashley, W. S., S. Strader, T. Rosencrants, and A. J. Krmenec, 2014: Spatiotemporal changes in tornado hazard exposure: The case of the expanding bull's-eye effect in chicago, illinois. Wea. Climate Soc., 6 (2), 175-193, doi:10.1175/wcas-d-13-00047.1, URL http://dx.doi.org/10.1175/ WCAS-D-13-00047.1.

Ashley, W. S., and S. M. Strader, 2016: Recipe for disaster: How the dynamic ingredients of risk and exposure are changing the tornado disaster landscape. Bulletin of the American Meteorological Society, 97, 767-786.

Begg, C., M. Ueberham, T. Masson, and C. Kuhlicke, 2016: Interactions between citizen responsibilization, flood experience and household resilience: insights from the 2013 flood in germany. International Journal of Water Resources Development, 33 (4), 591-608, doi: 10.1080/07900627.2016.1200961, URL https://doi.org/10.1080/07900627.2016.1200961.

Bohonos, J. J., and D. E. Hogan, 1999: The medical impact of tornadoes in north america. The Journal of Emergency Medicine, 17 (1), 67-73.

Bolin, R., and D. J. Klenow, 1983: Response of the elderly to disaster: An age-stratified analysis. The International Journal of Aging and Human Development, 16 (4), 283-296, doi:10.2190/ mqeg-yn39-8d5v-wkmp, URL https://doi.org/10.2190/mqeg-yn39-8d5v-wkmp.

Bosworth, S. L., 1999: The gendered terrain of disaster: Through women's eyes. American Journal of Sociology, 105 (3), 857-858, doi:10.1086/210369, URL https://doi.org/10.1086/210369. 
Coleman, T. A., and P. G. Dixon, 2014: An objective analysis of tornado risk in the United States. Weather and Forecasting, 29(2), 366-376.

Cutter, S. L., B. J. Boruff, and W. L. Shirley, 2003: Social vulnerability to environmental hazards. Social Science Quarterly, 84 (2), 242-261, doi:10.1111/1540-6237.8402002, URL https://doi. org/10.1111\%2F1540-6237.8402002.

Cutter, S. L., J. T. Mitchell, and M. S. Scott, 2000: Revealing the vulnerability of people and places: A case study of georgetown county, south carolina. Annals of the Association of American Geographers, 90 (4), 713-737, doi:10.1111/0004-5608.00219, URL https://doi.org/10. $1111 \% 2 F 0004-5608.00219$.

Dixon, P. G., A. E. Mercer, J. Choi, and J. S. Allen, 2011: Tornado risk analysis: Is Dixie alley an extension of tornado alley? Bull. Amer. Meteor. Soc., 92, 433-441.

Dixon, R. W., and T. W. Moore, 2012: Tornado vulnerability in Texas. Weather, Climate, and Society, 4, 59-68.

Donner, W. R., 2007: The political ecology of disaster: An analysis of factors influencing u.s. tornado fatalities and injuries, 1998-2000. Demography, 44 (3), 669-685, doi:10.1353/dem. 2007.0024, URL https://doi.org/10.1353\%2Fdem.2007.0024.

Donner, W. R., H. Rodriguez, and W. Diaz, 2012: Tornado warnings in three southern states: A qualitative analysis of public response patterns. Journal of Homeland Security and Emergency Management, 9 (2), doi:10.1515/1547-7355.1955, URL https://doi.org/10.1515/1547-7355. 1955.

Ellis, K. N., L. R. Mason, K. N. Gassert, J. B. Elsner, and T. Fricker, 2018: Public perception of climatological tornado risk in tennessee, USA. International Journal of Biome- 
teorology, 62 (9), 1557-1566, doi:10.1007/s00484-018-1547-x, URL https://doi.org/10.1007/ s00484-018-1547-x.

Elsner, J. B., T. Fricker, and W. D. Berry, 2018: A model for u.s. tornado casualties involving interaction between damage path estimates of population density and energy dissipation. Journal of Applied Meteorology and Climatology, doi:10.1175/jamc-d-18-0106.1, URL https://doi.org/10.1175/jamc-d-18-0106.1.

Emrich, C. T., and S. L. Cutter, 2011: Social vulnerability to climate-sensitive hazards in the southern united states. Weather, Climate, and Society, 3 (3), 193-208, doi:10.1175/2011wcas1092.1, URL https://doi.org/10.1175/2011wcas1092.1.

Enarson, E., A. Fothergill, and L. Peek, 2007: Gender and disaster: Foundations and directions. Handbook of Disaster Research, Springer New York, 130-146, doi:10.1007/ 978-0-387-32353-4_8, URL https://doi.org/10.1007/978-0-387-32353-4_8.

Fricker, T., and J. B. Elsner, 2015: Kinetic energy of tornadoes in the United States. PLoSONE, 10, e0131 090, doi:10.1371/journal.pone.0131090.

Fricker, T., J. B. Elsner, P. Camp, and T. H. Jagger, 2014: Empirical estimates of kinetic energy from some recent U.S. tornadoes. Geophysical Research Letters, 41, 4340-4346.

Fricker, T., J. B. Elsner, and T. H. Jagger, 2017a: Population and energy elasticity of tornado casualties. Geophysical Research Letters, doi:10.1002/2017gl073093, URL https://doi.org/10. $1002 \backslash \% 2 F 2017 \mathrm{gl} 1073093$.

Fricker, T., J. B. Elsner, V. Mesev, and T. H. Jagger, 2017b: A dasymetric method to spatially apportion tornado casualty counts. Geomatics, Natural Hazards and Risk, 8 (2), 1768-1782, doi:10.1080/19475705.2017.1386724, URL https://doi.org/10.1080/19475705.2017.1386724. 
Kahn, M. E., 2005: The death toll from natural disasters: the role of income, geography, and institutions. Review of economics and statistics, 87 (2), 271-284.

Kilijanek, T., and T. Drabek, 1979: Assessing long-term impacts of a natural disaster: A focus on the elderly. Gerontologist, 19, 555-566.

Klockow, K. E., R. A. Peppler, and R. A. McPherson, 2014: Tornado folk science in alabama and mississippi in the 27 april 2011 tornado outbreak. GeoJournal, 79 (6), 791-804, doi:10.1007/ s10708-013-9518-6, URL https://doi.org/10.1007/s10708-013-9518-6.

Lim, J., S. Loveridge, R. Shupp, and M. Skidmore, 2017: Double danger in the double wide: Dimensions of poverty, housing quality and tornado impacts. Regional Science and Urban Economics, 65, 1-15, doi:10.1016/j.regsciurbeco.2017.04.003, URL https://doi.org/10.1016/j. regsciurbeco.2017.04.003.

Mason, L. R., K. N. Ellis, B. Winchester, and S. Schexnayder, 2018: Tornado warnings at night: Who gets the message? Weather, Climate, and Society, 10 (3), 561-568, doi: 10.1175/wcas-d-17-0114.1, URL https://doi.org/10.1175/wcas-d-17-0114.1.

Masoomi, H., and J. W. van de Lindt, 2018: Fatality and injury prediction model for tornadoes. Natural Hazards Review, 19 (3), 04018 009, doi:10.1061/(asce)nh.1527-6996.0000295, URL https://doi.org/10.1061/(asce)nh.1527-6996.0000295.

McCreary, T., 2018: Shared Histories: Witsuwit'en-Settler Relations in Smithers, British Columbia 1913-1973. Creekstone Press, Limited, URL https://books.google.com/books?id= F4QtuQEACAAJ.

Mitchem, J. D., 2003: An analysis of the September 20, 2002, Indianapolis tornado: Public response to a tornado warning and damage assessment difficulties. Natural Hazards Center. 
Senkbeil, J. C., M. S. Rockman, and J. B. Mason, 2012: Shelter seeking plans of tuscaloosa residents for a future tornado event. Weather, Climate, and Society, 4 (3), 159-171, doi:10. 1175/wcas-d-11-00048.1, URL https://doi.org/10.1175/wcas-d-11-00048.1.

Senkbeil, J. C., D. A. Scott, P. Guinazu-Walker, and M. S. Rockman, 2013: Ethnic and racial differences in tornado hazard perception, preparedness, and shelter lead time in tuscaloosa. The Professional Geographer, 66 (4), 610-620, doi:10.1080/00330124.2013.826562, URL https: //doi.org/10.1080/00330124.2013.826562.

Sherman-Morris, K., 2009: Tornado warning dissemination and response at a university campus. Natural Hazards, 52 (3), 623-638, doi:10.1007/s11069-009-9405-0, URL https://doi.org/10. 1007/s11069-009-9405-0.

Simmons, K. M., and D. Sutter, 2005: WSR-88d radar, tornado warnings, and tornado casualties. Weather and Forecasting, 20 (3), 301-310, doi:10.1175/waf857.1, URL https://doi.org/10. 1175\%2Fwaf857.1.

Simmons, K. M., and D. Sutter, 2008: Tornado warnings, lead times, and tornado casualties: An empirical investigation. Weather and Forecasting, 23 (2), 246-258, doi:10.1175/ 2007waf2006027.1, URL https://doi.org/10.1175\%2F2007waf2006027.1.

Simmons, K. M., and D. Sutter, 2009: False alarms, tornado warnings, and tornado casualties. Weather, Climate, and Society, 1 (1), 38-53, doi:10.1175/2009wcas1005.1, URL https://doi. org/10.1175\%2F2009wcas1005.1.

Simmons, K. M., and D. Sutter, 2011: Economic and Societal Impacts of Tornadoes. American Meteorological Society, Boston, 282 pp. 
Simmons, K. M., and D. Sutter, 2014: Fatality prediction for the 2011 tornado season based on historical extreme weather data. Natural Hazards Review, 15 (3), 04014 005, doi:10.1061/(asce) nh.1527-6996.0000144, URL https://doi.org/10.1061/(asce)nh.1527-6996.0000144.

Strader, S. M., and W. S. Ashley, 2018: Finescale assessment of mobile home tornado vulnerability in the central and southeast united states. Weather, Climate, and Society, 10 (4), 797-812, doi: 10.1175/wcas-d-18-0060.1, URL https://doi.org/10.1175/wcas-d-18-0060.1.

Verbout, S. M., H. E. Brooks, L. M. Leslie, and D. M. Schultz, 2006: Evolution of the U.S. tornado database: 1954-2003. Weather and Forecasting, 21, 86-93.

Zahran, S., D. Tavani, and S. Weiler, 2013: Daily variation in natural disaster casualties: Information flows, safety, and opportunity costs in tornado versus hurricane strikes. Risk Analysis, 33, $1265-1280$. 
LIST OF TABLES

Table 1. Top ten unusually devastating tornadoes ranked by the difference in predicted and observed casualty rates.

Table 2. Socioeconomic and demographic profiles for the four communities chosen as examples of unusually devastating tornadoes. Age is given as a percentage of total population, race is given as a percentage of total population, household median income is given in 2010 USD, and poverty is given as a percentage of total population. 
TABLE 1 . Top ten unusually devastating tornadoes ranked by the difference in predicted and observed casualty rates.

\begin{tabular}{lcccc}
\hline Location & Date (Day-Month-Year) & Observed & Predicted & Difference (Observed - Predicted) \\
\hline Joplin, MO & $22-05-2011$ & 1308 & 131 & 1177 \\
Garland-Rowlett, TX & $26-12-2015$ & 478 & 81 & 397 \\
Gainesville, GA & $20-03-1998$ & 183 & 10 & 173 \\
Camilla, GA & $13-02-2000$ & 186 & 20 & 166 \\
Camilla, GA & $20-03-2003$ & 206 & 46 & 160 \\
Spencer, SD & $30-05-1998$ & 156 & 22 & 134 \\
Smithville, MS/Shottsville, AL & $27-04-2011$ & 160 & 41 & 119 \\
Columbus County, NC & $07-11-1995$ & 122 & 3 & 119 \\
Copeville, TX & $26-12-2015$ & 121 & 6 & 115 \\
Marmaduke, AR/Caruthersville, MO & $02-04-2006$ & 179 & 90 & 89 \\
\hline
\end{tabular}


TABLE 2. Socioeconomic and demographic profiles for the four communities chosen as examples of unusually devastating tornadoes. Age is given as a percentage of total population, race is given as a percentage of total population, household median income is given in 2010 USD, and poverty is given as a percentage of total population.

\begin{tabular}{lcccc}
\hline Variable & Spencer, SD & Garland-Rowlett, TX & Camilla, GA & Smithville, MS/Shottsville, AL \\
\hline Age (Under 18) & $30 \%$ & $30 \%$ & $30 \%$ & $23 \%$ \\
Age (18-24) & $2 \%$ & $9 \%$ & $11 \%$ & $9 \%$ \\
Age (25-44) & $19 \%$ & $29 \%$ & $27 \%$ & $25 \%$ \\
Age (45-64) & $25 \%$ & $24 \%$ & $19 \%$ & $26 \%$ \\
Age (Over 65) & $24 \%$ & $8 \%$ & $13 \%$ & $17 \%$ \\
Race (White) & $97 \%$ & $62 \%$ & $25 \%$ & $95 \%$ \\
Race (Black) & $1 \%$ & $14 \%$ & $70 \%$ & $3 \%$ \\
Race (Other) & $2 \%$ & $24 \%$ & $5 \%$ & $2 \%$ \\
Median Household Income & $\$ 21,250$ & $\$ 76,657$ & $\$ 22,485$ & $\$ 32,676$ \\
Poverty (Total family) & $7 \%$ & $9 \%$ & $35 \%$ & $10 \%$ \\
Poverty (Total population) & $11 \%$ & $12 \%$ & $38 \%$ & $15 \%$ \\
\hline
\end{tabular}




\section{LIST OF FIGURES}

Fig. 1. The number of tornado casualties by (A) month and by (B) hour. The size of the circle is proportional to the number of casualties.

Fig. 2. Predicted casualty rate versus observed casualty count. Points are shown only for tornadoes with at least 25 casualties. Values below the black line indicate tornadoes with more casualties than predicted using the regression model and the size of the circle is proportional to the number of underpredicted casualties.

Fig. 3. Unusually devastating tornadoes. The size of the circle is proportional to the number of underpredicted casualties.

Fig. 4. Spencer, South Dakota, Garland-Rowlett, Texas, Camilla, Georgia, and Smithville, Mississippi/Shottsville, Alabama. The orange circle indicates the location of the city or town and the size of the circle is proportional to the number of underpredicted casualties (see Fig. 3). 

to the number of casualties.

A

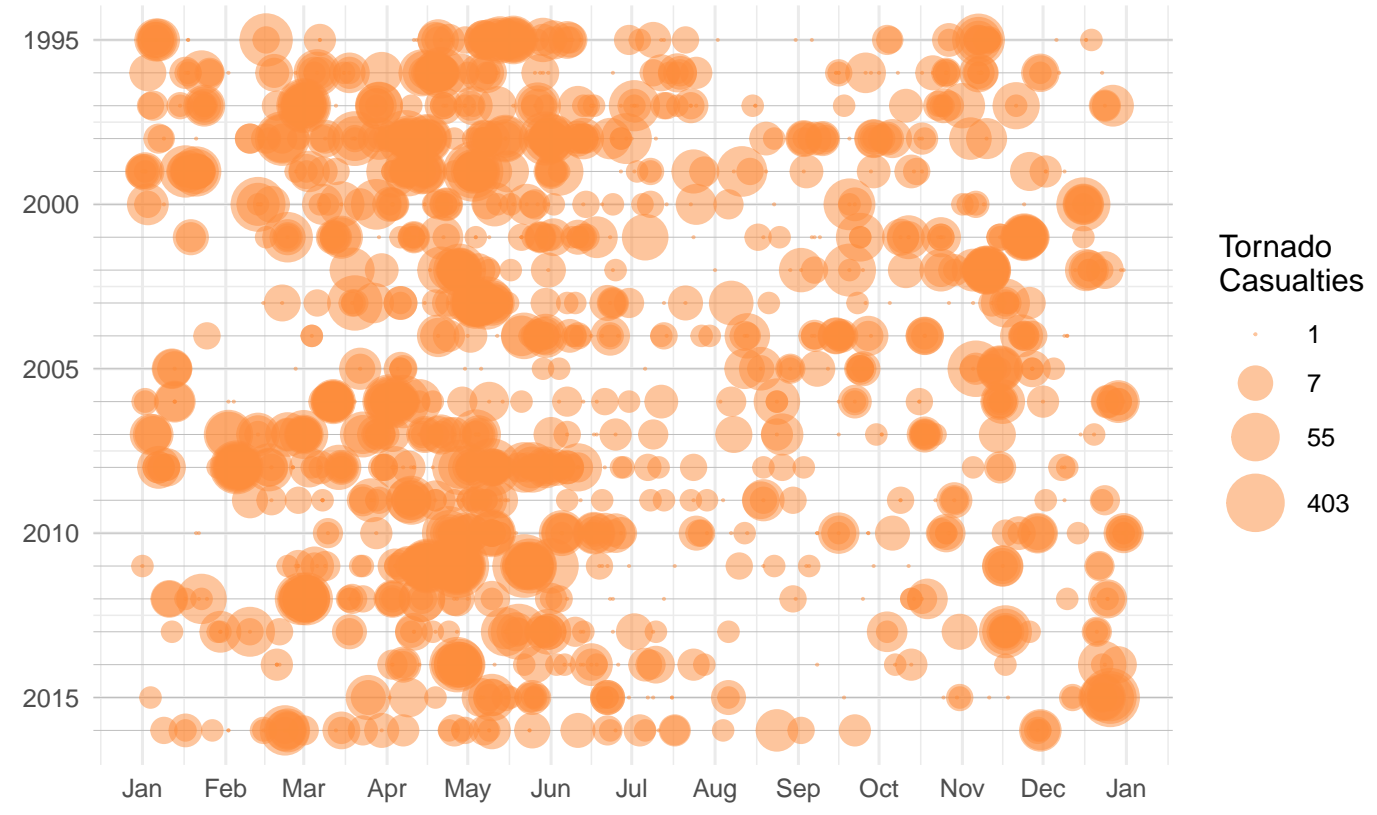

B

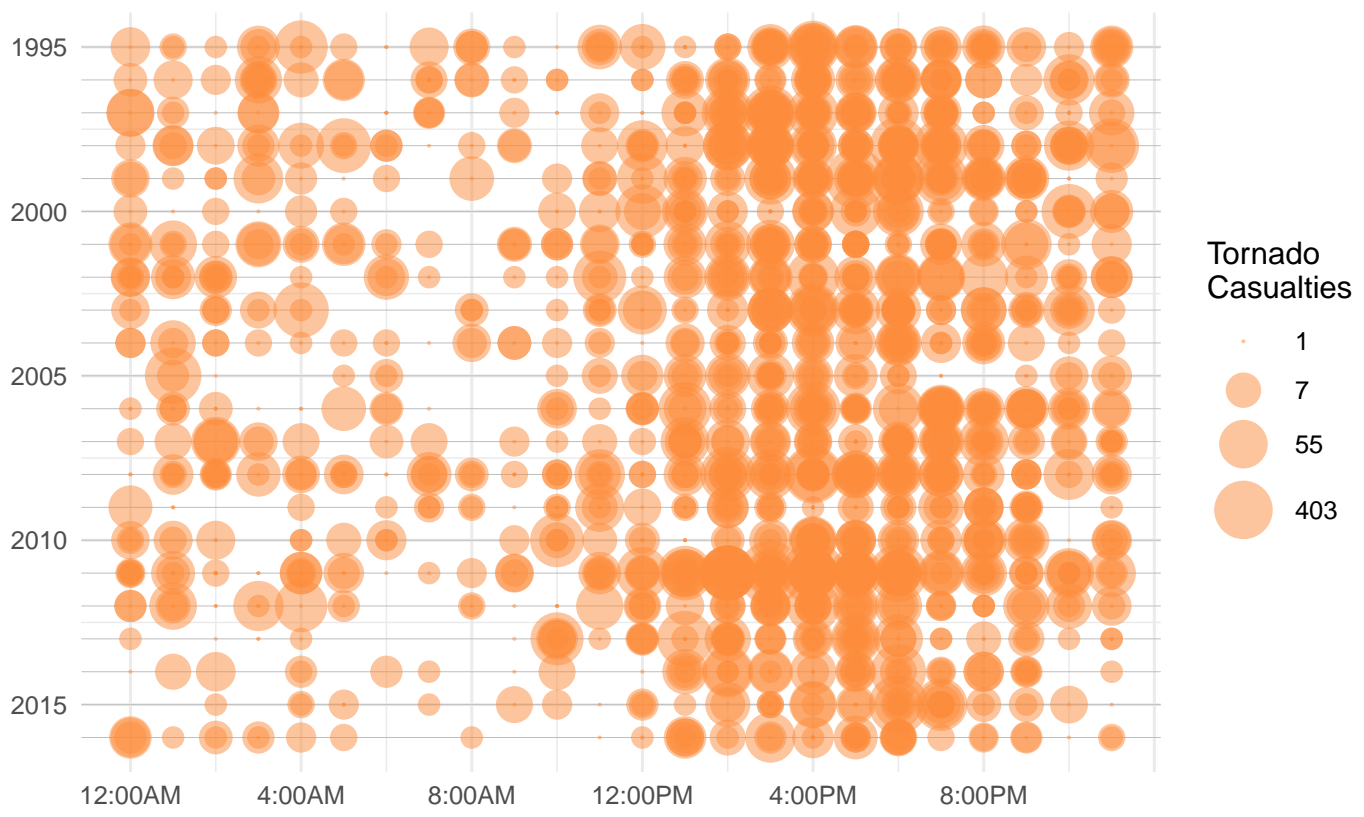


FIG. 2. Predicted casualty rate versus observed casualty count. Points are shown only for tornadoes with at least 25 casualties. Values below the black line indicate tornadoes with more casualties than predicted using the regression model and the size of the circle is proportional to the number of underpredicted casualties.

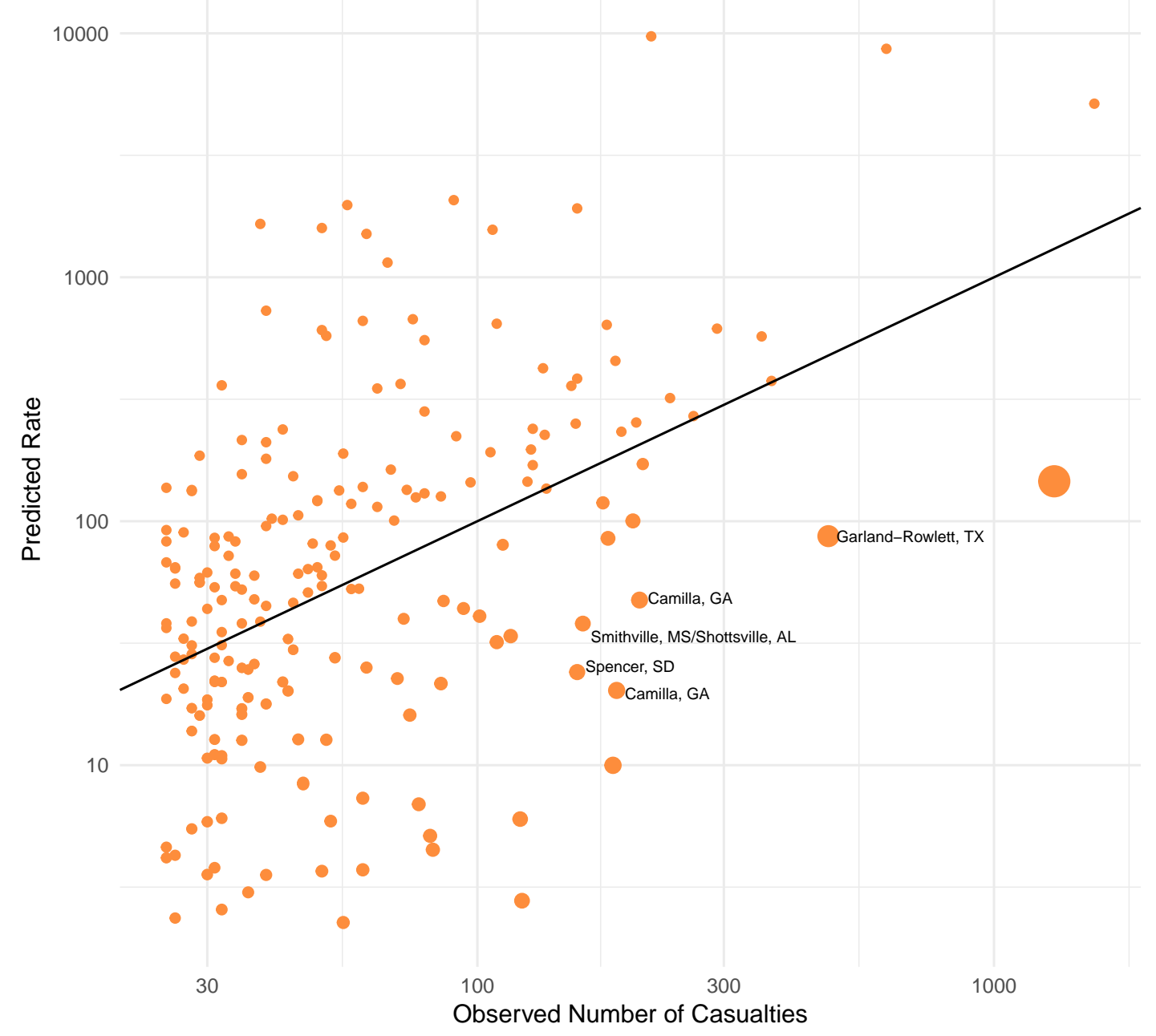



casualties.

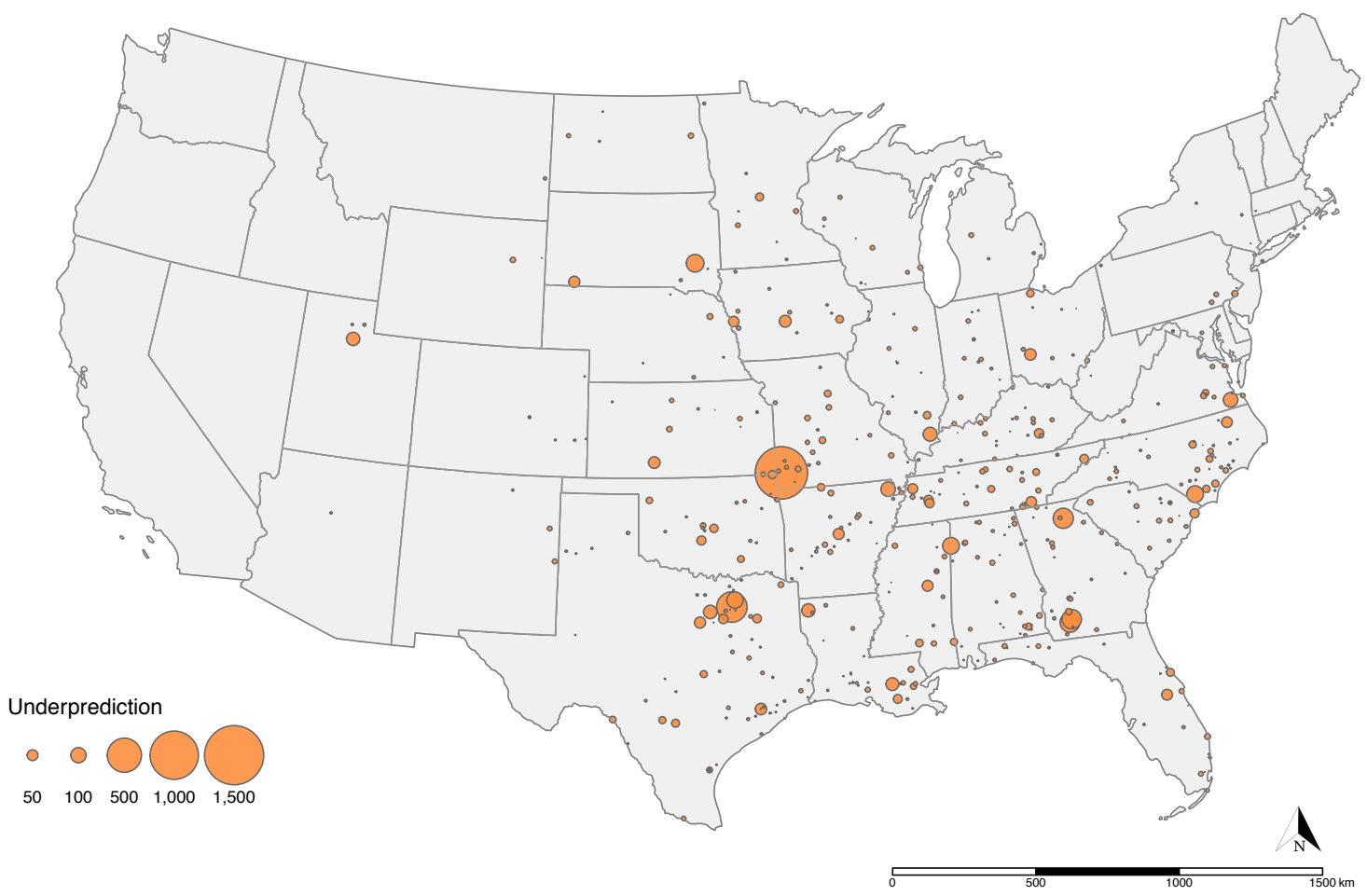


FIG. 4. Spencer, South Dakota, Garland-Rowlett, Texas, Camilla, Georgia, and Smithville, Mississippi/Shottsville, Alabama. The orange circle indicates the location of the city or town and the size of the circle is proportional to the number of underpredicted casualties (see Fig. 3).

Spencer, SD

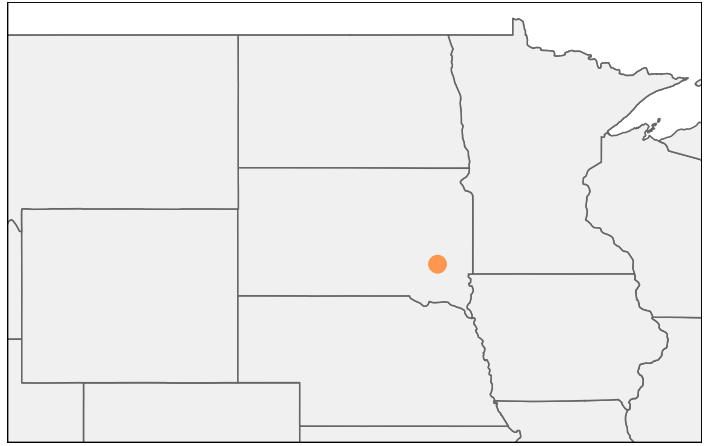

Camilla, GA

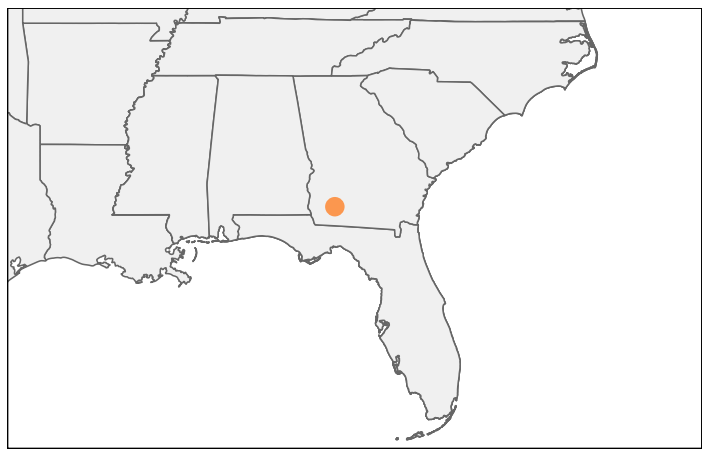

Garland-Rowlett, TX

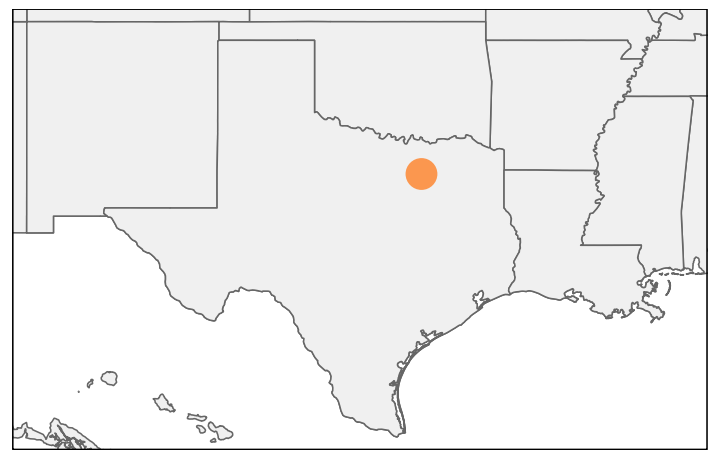

Smithville, MS/Shottsville, AL

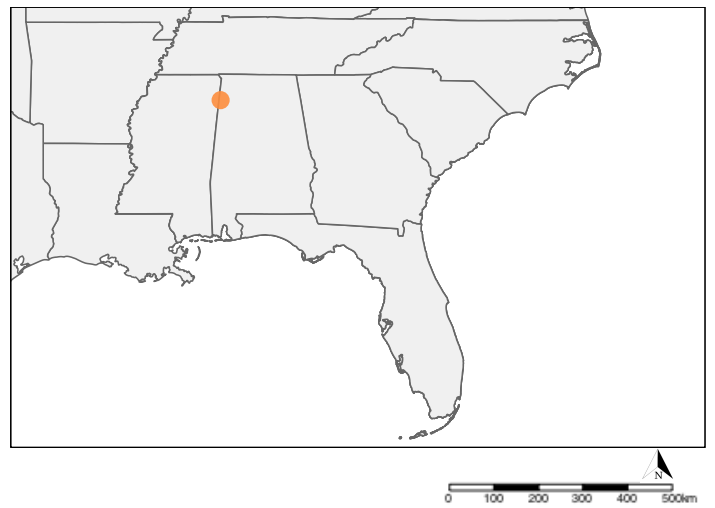

